\title{
MIDAS
}

Museus e estudos interdisciplinares

$8 \mid 2017$

Dossier temático "Objetos e museus: biografias, narrativas e vínculos identitários"

\section{A luneta de Bamberg no Museu de Astronomia e Ciências Afins: pesquisa e trajetória (1907-2016)}

The Bamberg elbow transit telescope at the Museum of Astronomy and Related Sciences: research and trajectory (1907-2016)

\section{Márcia Pinheiro Ferreira e Marcus Granato}

\section{OpenEdition Journals}

\section{Edição electrónica}

URL: http://journals.openedition.org/midas/1184

DOI: $10.4000 /$ midas. 1184

ISSN: 2182-9543

Editora:

Alice Semedo, Paulo Simões Rodrigues, Pedro Casaleiro, Raquel Henriques da Silva, Ana Carvalho

\section{Refêrencia eletrónica}

Márcia Pinheiro Ferreira e Marcus Granato, « A luneta de Bamberg no Museu de Astronomia e Ciências Afins: pesquisa e trajetória (1907-2016) », MIDAS [Online], 8 | 2017, posto online no dia 31 julho 2017, consultado no dia 21 abril 2019. URL : http://journals.openedition.org/midas/1184 ; DOI : 10.4000/midas. 1184

Este documento foi criado de forma automática no dia 21 Abril 2019.

\section{cc) (†) (2)}

Midas is licensed under a Creative Commons Attribution-NonCommercial-ShareAlike 3.0 International License 


\section{A luneta de Bamberg no Museu de Astronomia e Ciências Afins: pesquisa e trajetória (1907-2016)}

The Bamberg elbow transit telescope at the Museum of Astronomy and Related Sciences: research and trajectory (1907-2016)

\section{Márcia Pinheiro Ferreira e Marcus Granato}

\section{NOTA DO EDITOR}

Artigo recebido a 29.03.2017

Aprovado para publicação a 24.07.2017

\section{Introdução}

O Museu de Astronomia e Ciências Afins (MAST) detém sob sua guarda parte do património histórico móvel e imóvel originário do Observatório Nacional (ON). As duas instituições dividem um campus de $44000 \mathrm{~m}^{2}$ no bairro imperial de São Cristóvão, no Rio de Janeiro (Brasil). O projeto de conservação e restauro da luneta meridiana acotovelada n.․ 10783 de Bamberg (fig. 1) e do seu pavilhão realizou-se no âmbito dos programas de conservação desenvolvidos pelo MAST para a preservação desses bens. 


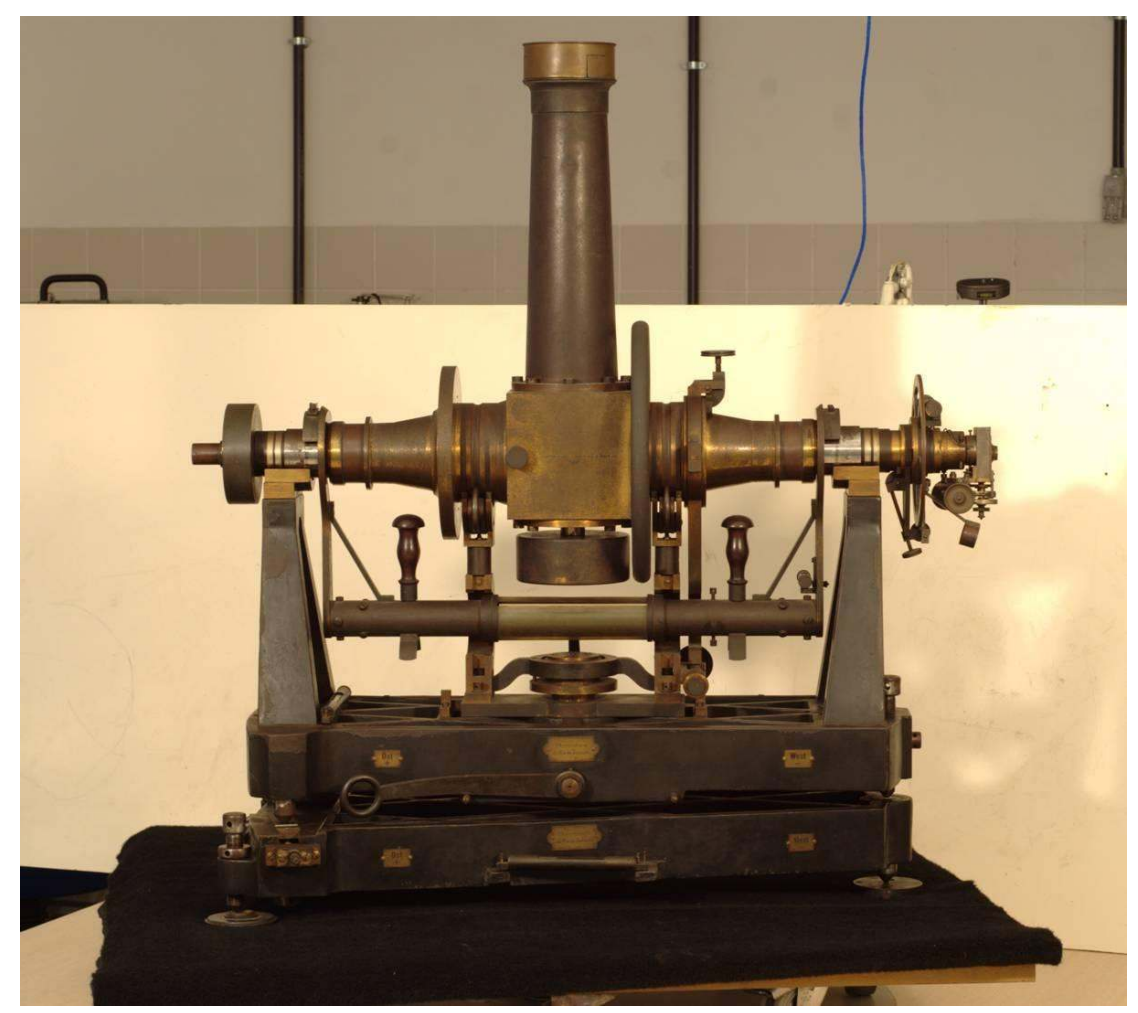

Fig. 1 - Luneta n. ${ }^{\circ} 10783$ de Bamberg na bancada do laboratório, 2013, MAST

Fotografia de Ricardo Marroquim

2 As pesquisas realizadas e apresentadas em parte neste texto tiveram por objetivo caracterizar a importância histórica e documental e identificar a carga simbólica associada à luneta Bamberg n.. 10783. Convivendo com diversos instrumentos, alguns dos quais não saíram das suas caixas e outros que pouco operaram, a luneta Bamberg n.ำ 10783 atravessou sete décadas em operação (1907-1974).

Neste estudo optámos pela aplicação de uma metodologia de pesquisa qualitativa apoiada na análise de fontes primárias e secundárias, e nos factos que possibilitaram a construção da trajetória de uso da luneta Bamberg n.․ 10783, sendo o instrumento considerado, igualmente, como documento da sua história. Para tal foram identificados e analisados diversos fundos e documentos arquivísticos (Fundo da Hora Legal Brasileira, sob a guarda do ON; Fundo ON, sob a guarda do Arquivo de História da Ciência no MAST; documentos do banco de Relatórios Ministeriais e legislação brasileira) relacionados com a história do objeto; documentos audiovisuais e documentação museológica pertencente à Coordenação de Museologia do MAST; depoimentos de antigos funcionários do ON e fontes secundárias em bibliotecas e bancos digitais de publicações académicas sobre aspetos diversos relacionados com o instrumento.

4 Ao propor uma abordagem antropológica da história dos museus através da biografia das coisas, Samuel Alberti propôs que se estudassem as coleções através das trajetórias de itens específicos, analisando as relações existentes entre um item, pessoas e outros objetos. Alberti trouxe para os museus de ciência perguntas sugeridas por Igor Kopytoff ${ }^{1}$ para escrever biografias de pessoas: quais são os momentos-chave na trajetória de uso desta "coisa"? Como é que o seu estatuto foi alterado ao longo da sua vida? Quais foram as suas fases mais significativas? o que o torna diferente de outros exemplares nesta e noutras coleções? Como é que o contexto sociopolítico condicionou a sua trajetória? 
(Kopytoff 1986, 66-67; Alberti 2005, 560). Estas perguntas foram também utilizadas no âmbito da pesquisa realizada sobre a luneta.

O conjunto paisagístico do campus ON-MAST, incluindo o conjunto de edificações históricas e as coleções que compuseram o acervo MAST no momento da sua criação, foi tombado pelo Instituto do Patrimônio Histórico e Artístico Nacional (IPHAN) em 1986², e pelo Instituto Estadual de Patrimônio Cultural (NEPAC) em 1987, sendo dos poucos acervos de ciência e tecnologia (C\&T) patrimonializados no Brasil.

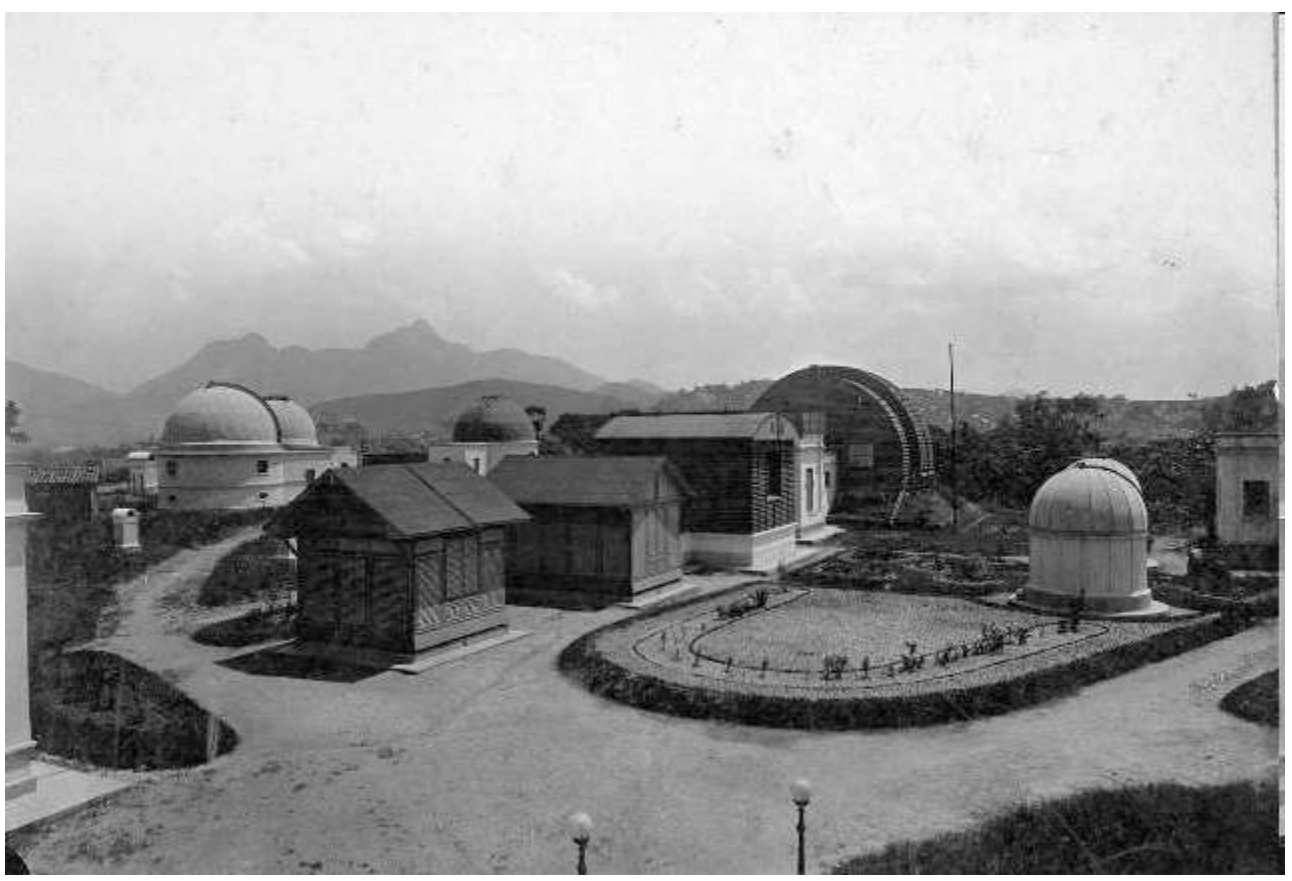

Fig. 2 - Sítio de observação do céu, onde se destaca o pavilhão Bamberg, ca. 1920

Acervo MAST, autoria desconhecida

6 Este artigo apresenta os resultados obtidos a partir das pesquisas desenvolvidas, iniciando-se sobre aspetos relacionados com o fabricante da luneta, passando pelos períodos de atividade na sua função original até o seu período de musealização no MAST. Para tal, cumpre esclarecer que uma luneta meridiana não dispõe de tanta mobilidade do eixo como outros telescópios, acompanhando apenas o meridiano escolhido pelo observatório de norte a sul, passando pelo zénite. A versão acotovelada das lunetas meridianas representava um avanço que o Brasil não acompanharia senão a partir da viragem do século XX.

\section{O fabricante do objeto: Bamberg}

Carl Bamberg (1847-1892) havia estagiado com Carl Zeiss (1816-1888), de Jena (Alemanha), entre 1862 e 1866, trabalhando no fabrico de instrumentos científicos nas empresas Sprenger e Pistor \& Martins, ambas localizadas em Berlim. Em 1871 já havia fundado a sua própria oficina em Berlim (Wolfschmidt 2012, 179). A fábrica estava em grande atividade quando Bamberg faleceu em 1892, e a sua esposa Emma (1847-1937) em conjunto com o diretor técnico, Theodor Ludewig (1854-1912), passou a dirigir a empresa (Wolfschmidt 2012, 190). 
8 Em 1904, o filho Paul Bamberg tornou-se diretor e lançou o modelo Bamberg de luneta meridiana acotovelada com base de Dollen e micrómetro elétrico na Exposição Universal de St. Louis (Bamberg 1904, 7-8), modelo que, possivelmente, começara a ser construído ainda durante a gestão da fábrica pela sua mãe.

Os instrumentos meridianos são instrumentos de observação da passagem de um astro pelo meridiano estabelecido por um observatório. Podem ser fixos, abrigados num pavilhão com fenda de norte a sul na cobertura, ou portáteis para expedições. Assim como um teodolito e um círculo meridiano, as lunetas meridianas alinham-se com o meridiano do Observatório (uma linha no sentido norte-sul que o seu eixo mecânico permite acompanhar). As lunetas meridianas acotoveladas fixas e os círculos meridianos portáteis, por sua vez, alinham-se sem que o astrónomo precisasse de se deitar ao apontar o zénite, uma vantagem ergonómica na determinação do tempo sideral.

Baron Zach, que concebeu o sistema acotovelado, encomendou ao fabricante Reichenbach em 1811, construtor de teodolitos repetidores, e recebeu o modelo em 1815, em Nápoles. ${ }^{3}$ Na luneta meridiana acotovelada, ao invés da lente ocular estar na extremidade oposta à objetiva, no mesmo eixo, encontra-se numa extremidade do eixo horizontal leste-oeste, em oposição a um contrapeso que equilibra o eixo horizontal. No centro do cruzamento dos dois eixos há um cubo dentro do qual um espelho ou prisma quebra o percurso dos raios de luz que formarão a imagem para que cheguem à lente ocular, daí a designação broken transit ou elbow transit telescopes. $\mathrm{O}$ eixo horizontal, na acotovelada, contém a ocular e também gira $180^{\circ}$ para transferir a ocular de leste para oeste. A média entre a observação a leste e a observação a oeste, dará o local exacto da perpendicularidade do meridiano celeste do Observatório.

O exemplar exposto por Paul Bamberg em 1904 era um pouco menor do que o exemplar n. 10783 deste modelo, encomendado pelo ON. A distância focal e a abertura da lente objetiva são menores no exemplar da Exposição Universal, respetivamente 0,65 $\mathrm{m}$ e 68 mm, do que na luneta n. .10783 adquirida pelo ON: $0,90 \mathrm{~m} \mathrm{e} 80 \mathrm{~mm}^{4}$.

12 A Bamberg fabricou instrumentos astronómicos, geodésicos, geomagnéticos e sismógrafos de grande precisão até 1921, quando, em consequência do fim da I Grande Guerra, a progressiva queda dos lucros obrigou o genro de Carl Bamberg a juntar-se com outras fábricas e a mudar o nome para Askania Werke A.G. (Wolfschmidt 2012, 190).

\section{O período relativo ao Observatório Nacional no Morro do Castelo}

O ON não esteve sempre no Morro de São Januário, em São Cristóvão. ${ }^{5}$ A sua antiga sede, desde 1850, foi o Morro do Castelo, no centro do Rio de Janeiro (Morize 1987). Apesar da instabilidade do solo no Morro do Castelo e da degradação da antiga igreja jesuíta que abrigou o Observatório desde 1850, a pesquisa do astrónomo Henrique Morize oferece provas suficientes da atividade institucional em sismologia, meteorologia, observações equatoriais e observações meridianas no Imperial Observatório do Rio de Janeiro, no Morro do Castelo, e do uso da luneta Bamberg n.. 10783, pelo menos desde 1909, numa sala construída a sudoeste, no então Observatório Nacional, já no período republicano brasileiro.

A publicação tardia da cópia dos manuscritos da pesquisa de Henrique Morize, entregues ao ON pelo seu filho em 1952 (Morize 1987, 7), revelou a exaustiva consulta que o ex- 
diretor fizera em fontes primárias de documentação. Foi somente em 1987 que o MAST, recém-criado sob a direção do astrónomo Ronaldo Rogério de Freitas Mourão, tomou para si o compromisso de publicar o conteúdo para comemorar os 160 anos do Observatório.

Considerando os documentos que indicam a aquisição da luneta n.. 10783 de Bamberg anteriores ao ano de 1908, a nomenclatura da instituição neste período seria Observatório do Rio de Janeiro, exatamente o que está gravado na placa de latão do fornecedor, aparafusada à luneta (ver fig. 5a). No ofício n. 73 de 10 de junho de 1904, o diretor do ON solicita ao diretor da Estrada de Ferro Central do Brasil «que seja ligada a sala meridiana d'este Observatório à Repartição sob vossa digna direção a fim de permitir a troca dos signaes telegraphicos entre este observatório e a Estação» (ON 1904, s/p). Este facto ocorre no mesmo ano em que Paul Bamberg lançou o seu modelo elétrico de luneta meridiana acotovelada, com os dispositivos especiais para determinação da latitude pelo método de Horrebow-Talcott. Percebe-se, no documento, que o tom utilizado é elogioso como o que o ON empregaria no Relatório Ministerial referente ao ano de 1907 (Brasil 1908), ao referir-se à nova aquisição do ON. Este relatório ministerial citava a aquisição de novos instrumentos, enquanto o Observatório aguardava um espaço mais amplo e investimento em pessoal técnico habilitado. É o documento mais antigo localizado que se refere à luneta Bamberg n.. 10783 .

Não é possível afirmar quem foi o astrónomo responsável pela sua encomenda, mas é possível inferir que a sua instalação tenha sido feita pelo astrónomo Domingos Fernandes da Costa (1882-1956), que se responsabilizava por montar, instalar e retificar (Barroso Jr. 1961) os instrumentos fixos. O mais antigo relatório de observação do céu com a luneta Bamberg n.․ 10783 encontrado foi feito justamente por Domingos da Costa em 1909. Na publicação de Morize (1987, 170-171), há dois relatos de operação em Talcott com a luneta Bamberg n.․ 10783, em 1909 e em 1912, ambos na antiga sede do ON, no Morro do Castelo.

17 A fim de compreender a trajetória da luneta Bamberg n.. 10783 dentro da única instituição onde operou, convém conhecer os avanços e as dificuldades que a instrumentação para observações meridianas enfrentou no ON. Muitas situações de goteira e infestação por cupins podem ter significado a perda de importantes documentos. Os recursos para compra de instrumentos, não podendo ser aplicados na ampliação do espaço de guarda para o material, resultaram em prejuízos quanto à conservação dos instrumentos que, ainda embalados, muitas vezes se danificavam nas caixas. Já em operação a SW neste ano, a luneta n. 10783 de Bamberg também enfrentava goteiras, assim como viria a acontecer, segundo a oficina do ON, também na nova sede em São Cristóvão (ON 1916a; ON 1916b; Brandão 1999).

18 Segundo Morize (1987, 144-145), em 1910, o desmoronamento da janela no primeiro pavimento, onde funcionava a biblioteca, foi decisivo para que o Ministro estabelecesse uma comissão de engenheiros para definição do novo terreno para a mudança do Observatório. Foi escolhido o Morro de São Januário em 1911. De 1911 a 1913, os pavilhões para as cúpulas equatoriais foram construídos em alvenaria e os abrigos meridianos pequenos em madeira, que não dependiam de mão de obra alemã durante a I Grande Guerra, foram montados em seguida (ON 1913; ON 1914a; ON 1914b; ON 1914c). O material do Pavilhão Bamberg e do Pavilhão Gautier, ambos de projeto alemão, foi adquirido, mas permaneceu em depósito enquanto aguardava o fim da I Guerra Mundial, determinando problemas de conservação das partes metálicas (ON 1914d; ON 1915a; ON 1915b).

O ofício de 22 de setembro de 1914 do Observatório Nacional do Rio de Janeiro, enviado ao engenheiro do Ministério da Agricultura, comunicava que três engenheiros da Prefeitura 
afirmavam que o prédio do Castelo estava condenado (em situação próxima ao desabamento), depois da chuva do dia 19: a luneta Bamberg n.. 10783 ainda funcionava no Castelo. A sala alagou porque a cúpula apresentava furos decorrentes da ação da corrosão. Faltavam, além de recursos, funcionários de manutenção instrumental e predial. Na fig. 3 , a vista $\mathrm{W}$ do terraço do Observatório no Morro do Castelo permite notar a cúpula da equatorial, a sala que já existia em 1905 e uma nova sala bem menor, a sala meridiana da Bamberg (ON 1910). A fig. 4 apresenta um registo fotográfico da fachada Sul do Observatório Nacional, com a parede da sala meridiana pequena, à beira das ruínas, em função da demolição do Morro do Castelo, na reforma do centro da cidade feita por Pereira Passos ${ }^{6}$.

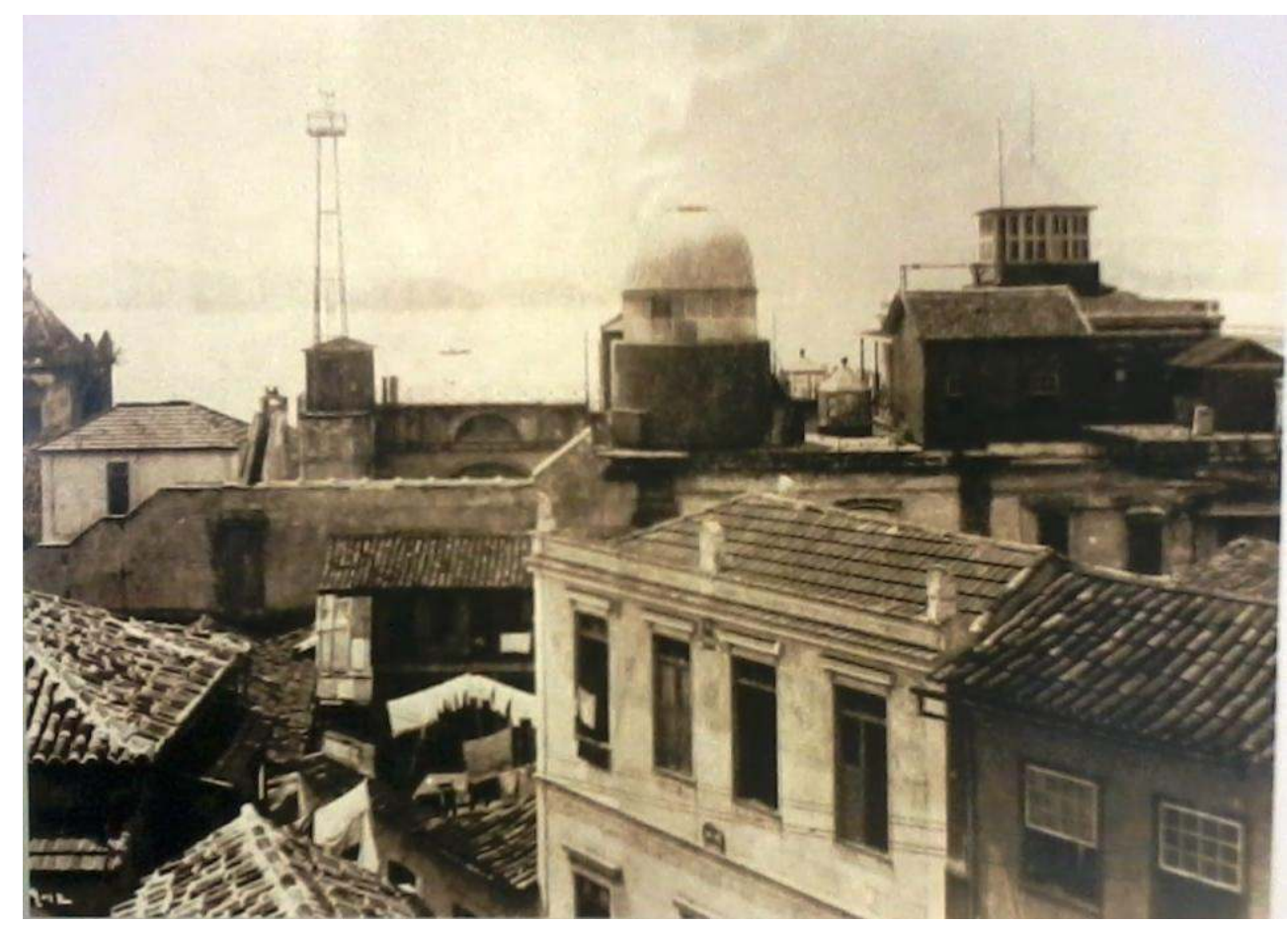

Fig. 3 - Observatório, 1912

Fotografia de Augusto Malta

Em 1921 e 1922, durante as demolições do Morro do Castelo, os astrónomos Domingos Fernandes da Costa, Allyrio de Mattos e Auto Barata Fortes ainda subiriam ao pilar SW para determinar a diferença de longitude entre a antiga coordenada geográfica da luneta n.o 10783 de Bamberg, no Castelo, e o seu novo pilar no Morro de São Januário. Para isso foram utilizados, além da luneta, outros três instrumentos de Bamberg, todos círculos meridianos portáteis de fabricação n.. 2646, n.ํ 11745 e n.. 11845 (Morize 1987, 169-171). 


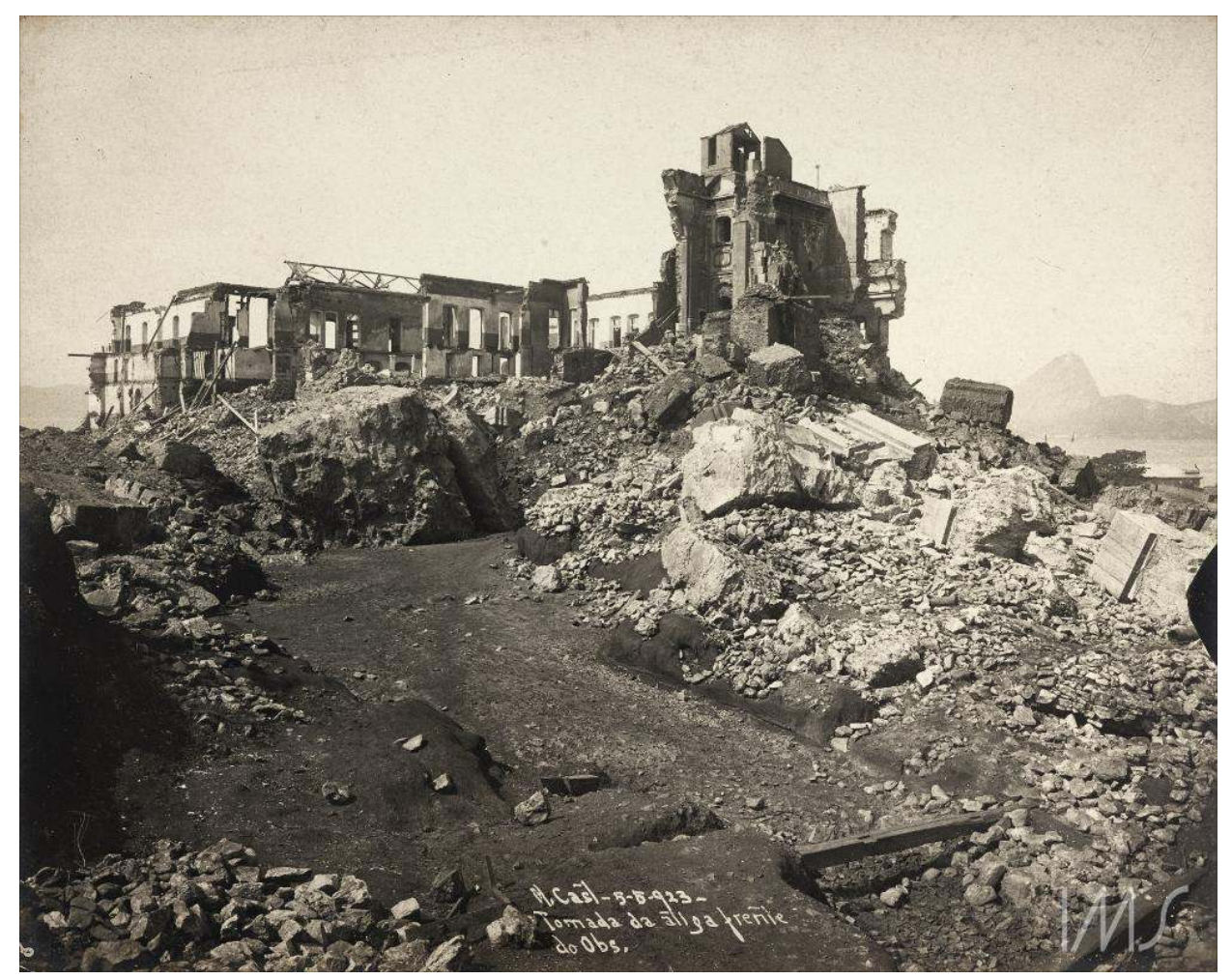

Fig. 4 - Fachada Sul do ON, com a parede da sala SW no topo, à beira das ruínas, 5 de maio de 1923 Fotografia de Augusto Malta

Destes instrumentos meridianos relacionados com a luneta n.o 10783, apenas o círculo portátil n.. 2646 de Bamberg estava no depósito do ON na ocasião da incorporação no acervo do MAST. Há ainda no acervo MAST três teodolitos e um declinómetro de Bamberg, não relacionados com as operações do objeto desta análise.

\section{A luneta n. ${ }^{\circ} 10783$ de Bamberg e o seu uso no Morro de São Januário}

22 O conjunto arquitectónico da luneta n. 10783 de Bamberg compõe-se por: 1) o pavilhão médio de Carl Zeiss no Morro de São Januário, que é tratado como Pavilhão Bamberg; 2) um abrigo da sua mira, distante dele na direção norte (N); e 3) um abrigo do seu colimador ${ }^{7}$ ou lente colimadora que, focalizada pela luneta através da janela $\mathrm{N}$, encontra a mira a seguir. O relógio e o cronógrafo que ocupavam este pavilhão, no momento da criação do MAST, foram realmente objetos relacionados com a luneta n. 10783 de Bamberg na última fase da sua trajetória de uso: o cronógrafo n.. 361555 da Marconi's Wireless Telegraph, de Londres, catalogado no Museu como MAST1996/586, e uma pendula Strasser, até 1964, que, quando infestada de cupim, foi substituída pela pendula n.. 1201 da L. Leroy\&Co, de Paris, registada como MAST1994/426 3/3. O mobiliário do Pavilhão compõe-se, então, de um armário embutido construído em 1963 (Brandão 1999, 40), da sapata de sustentação da pendula Leroy, do armário do cronógrafo Marconi e de um conjunto de mesa e cadeira, que foi identificado com o auxílio do astrónomo Oliveiros Cardoso Tavares, em 1993, quando este e Odílio Brandão, antigo chefe das Oficinas do ON, se dispuseram a colaborar com o MAST, recém-criado, e concederam uma longa entrevista (Tavares 1993) ${ }^{8}$, justamente dentro do Pavilhão da luneta meridiana 
acotovelada n. 10783 de Bamberg. Esta entrevista, além de esclarecedora sobre o funcionamento e manutenção do instrumento, inclui momentos preciosos, como as recordações sobre os usuários da luneta e a constituição do retículo de reposição ao original rompido no micrómetro com fio de teia de uma aranha específica, capturada na Quinta da Boa Vista, próxima do Morro de São Januário, e criada dentro de uma sala no Observatório Nacional.

O Serviço da Hora foi amplamente contemplado pelo astrónomo Oliveiros Cardoso Tavares na entrevista que concedeu à equipe de Museologia do MAST. Dos 37 anos de trabalho no Observatório Nacional, o Prof. Oliveiros Cardoso Tavares dedicou 20 anos à observação do céu pela luneta meridiana acotovelada Bamberg. Nos momentos iniciais da entrevista, ao lado da luneta, o astrónomo apresenta o pavilhão, a função da fenda da sua trapeira, apresenta a luneta, explica o seu funcionamento na observação da passagem de astros pelo meridiano e o seu sistema ótico acotovelado, que reflete a $90^{\circ}$ na lateral do instrumento a imagem capturada pela lente objetiva (Tavares 1993).

No Anuário do Observatório em 1917, identifica-se a rotina do plantonista de observações meridianas:

[...] Em resumo, o programa de observações é o seguinte:

Fazer duas pontarias sobre a mira.

Ler o nível.

Fazer quatro pontarias sobre a estrella.

Ler o nível.

Fazer duas pontarias sobre a mira

Inversão

Fazer duas pontarias sobre a mira.

Ler o nível.

Fazer quatro pontarias sobre a estrella.

Ler o nível. (ON 1917, s/p)

As observações meridianas de passagem de estrelas serviam para determinação do tempo estelar ou sideral, que somente se obtinha após cálculos, o que difere do tempo solar. Para determinar o período sinódico ou tempo solar bastava olhar para o céu, sem a necessidade de cálculos. $\mathrm{O}$ astrónomo Henrique Morize distingue o tempo pelo sol como:

[...] o intervalo entre duas passagens pelo mesmo meridiano, 24 horas, ou um dia chamado solar ou verdadeiro. § Essa duração não é porém constante, e em tempo relativamente moderno abandonou-se o dia solar que foi substituído por um sol fictício, chamado médio, cuja marcha é regular, o que tem a grande vantagem de tornar todos os dias de igual duração. (Morize 1987, 162)

O tempo médio é o que regula a atividade humana, mas existe ainda um dia de duração mais curta, o tempo sideral, que é medido pela «duração da rotação das estrelas ao redor do meridiano» (Morize 1987, 162), um tempo calculado pelos astrónomos, mas que não é usado pelos leigos. Esse foi o princípio usado para a determinação da hora durante várias décadas. Segundo o astrónomo Jair Barroso Jr., também colaborador do MAST e aposentado do ON:

A cada estrela observada, eram necessárias determinações do nível de bolha porque as inversões da luneta meridiana afetavam frequentemente seu posicionamento; era preciso também escolher estrelas convenientemente posicionadas no céu para corrigir o azimute das observações. Conforme foi mencionado anteriormente, as observações meridianas realizadas no ON compuseram com as de outros países pertencentes ao esquema do BIH o quadro de resultados que permitiu a deteção das irregularidades de rotação da Terra, descartando-a como referência de tempo. (Barroso Jr 2013, s/p) 
Ainda segundo o astrónomo, foi assim que os observatórios astronómicos descobriram «que o planeta não era um bom relógio. A rotação da Terra não serve como relógio, mas a translação é mais precisa, mais próxima do tempo $\mathrm{T}$ da mecânica que é uniforme» (Barroso Jr. 2011, min 35). O Serviço da Hora do ON dependia das lunetas meridianas quando se pensava que o intervalo entre duas passagens consecutivas de uma estrela pelo meridiano completava as $24 \mathrm{~h}$, num tempo em que se pensava que a rotação da Terra era regular. Em 1935, as comparações entre as observações astronómicas e os relógios de quartzo em Postdam (Alemanha)

[...] confirmaram variações irregulares, já previstas teoricamente na rotação da Terra, variações essas detetadas inicialmente no limiar da precisão da época utilizando pêndulas tipo Shortt, tendo o ON contribuído inclusive para tal fim junto aos demais observatórios que compunham a hora internacional na ocasião, à responsabilidade do Bureau International de l'Heure. (Barroso Jr 2013)

Em 1939, o Royal Observatory de Greenwich comprou o seu primeiro relógio de quartzo. Esse tipo de relógio, apesar de tender a adiantar, foi um grande avanço por não depender do movimento da Terra (Barroso Jr. 2011). Novos equipamentos chegaram ao ON para operarem em simultâneo com as observações meridianas. Mais avanços tecnológicos se sucederam. No início da década de 1960, começou a funcionar no Serviço da Hora do ON o primeiro padrão atómico de césio, mas ainda em paralelo com as observações meridianas, que atendiam às pesquisas quanto à irregularidade da rotação da Terra, entre outros estudos de passagem de astros pelo meridiano do Observatório.

Não foi possível determinar os exemplares de cronómetros e pendulas relacionados com as duas lunetas meridianas existentes no Morro do Castelo (Dollond e Bamberg), por não serem discriminados nos boletins publicados pelo Observatório. Das planilhas de observação meridiana neste período, muito se perdeu em degradação e/ou descarte de papéis. Apesar da perda de diversos documentos do $\mathrm{ON}$ referentes à antiga sede no Morro do Castelo, o exame do objeto como documento oferece questões, elementos de pesquisa e até respostas sobre a sua trajetória.

Brandão e Tavares na entrevista realizada usaram a expressão «um pouco antes de 76» como data aproximada da aposentadoria da luneta n.. 10783 de Bamberg. Segundo os entrevistados, a razão principal da sua aposentadoria foi a falta de astrónomos para as pesquisas meridianas, num momento de expansão das novas tecnologias de precisão da determinação da Hora Legal Brasileira. $O$ outro motivo estava relacionado com problemas de funcionamento, como se pode constatar no relatório de observação de Arthur Eugênio, a 25 de setembro de 1974: «discordância entre os valores do azimute» (ON 1974, s/p).

31 Quanto ao levantamento das publicações de pesquisa, de difusão e de divulgação geradas com dados fornecidos pelo instrumento, podemos inferir que a Bamberg n. .10783 contribuiu para as seguintes publicações: os Anuários do Observatório ao menos desde 1911'; os dados de observação enviados aos boletins do Bureau International de l'Heure, de 1922 a 1960 (Armando 1959, 13); e a publicação do Comité Spécial de l'Ánnée Geophysique Internationalle no Ano Geofísico Internacional (ON 1954).

\section{O objeto musealizado}

O termo musealização foi cunhado por Zbyněk Stránský (1926-2016) para descrever a transposição de um objeto do seu contexto de uso para um contexto museológico, tornando-o património. $\mathrm{O}$ objeto passa a ser tratado como documento, como 
representação da realidade ou, para Stránsky, dotado de qualidades museais (Stránský 1995 apud Soares 2017, 66).

33 Soares (2017) discute as implicações sociais e políticas da atribuição de valor como instrumento de demarcação de poder e dominação que, "descolonizado" no século XXI, permitirá entender a musealização como negociação cultural:

Musealização é um ato de valoração em que um emissor produz sentidos e constrói patrimônios e musealidade a partir de um regime de valor específico e culturalmente fundado. A complexificação de tal conceito se mostra ainda mais aguda na medida em que musealiza-se em uma dada cultura, objetos que foram forjados em outra. (Soares 2017, 66)

34 A luneta n. 10783 de Bamberg foi incorporada por depósito do ON no MAST no momento de criação do Museu, a 8 de março de 1985, iniciando então o seu processo de musealização. Etapas como a sua conservação regular, registo e documentação, exposição e pesquisa relacionada com a sua funcionalidade e história fazem parte desse processo. Nesse contexto, o exame do objeto museológico como documento revela indícios ou até a constatação de factos relevantes nas suas trajetórias de uso e no museu.

35 Os resultados aqui apresentados, obtidos no âmbito da Coordenação de Museologia do MAST, articulam-se com o exame detalhado do objeto, por exemplo, as placas do fornecedor e do comprador na base da luneta que documentam o período limite da sua aquisição: até 1907 (fig. 5a e 5b).

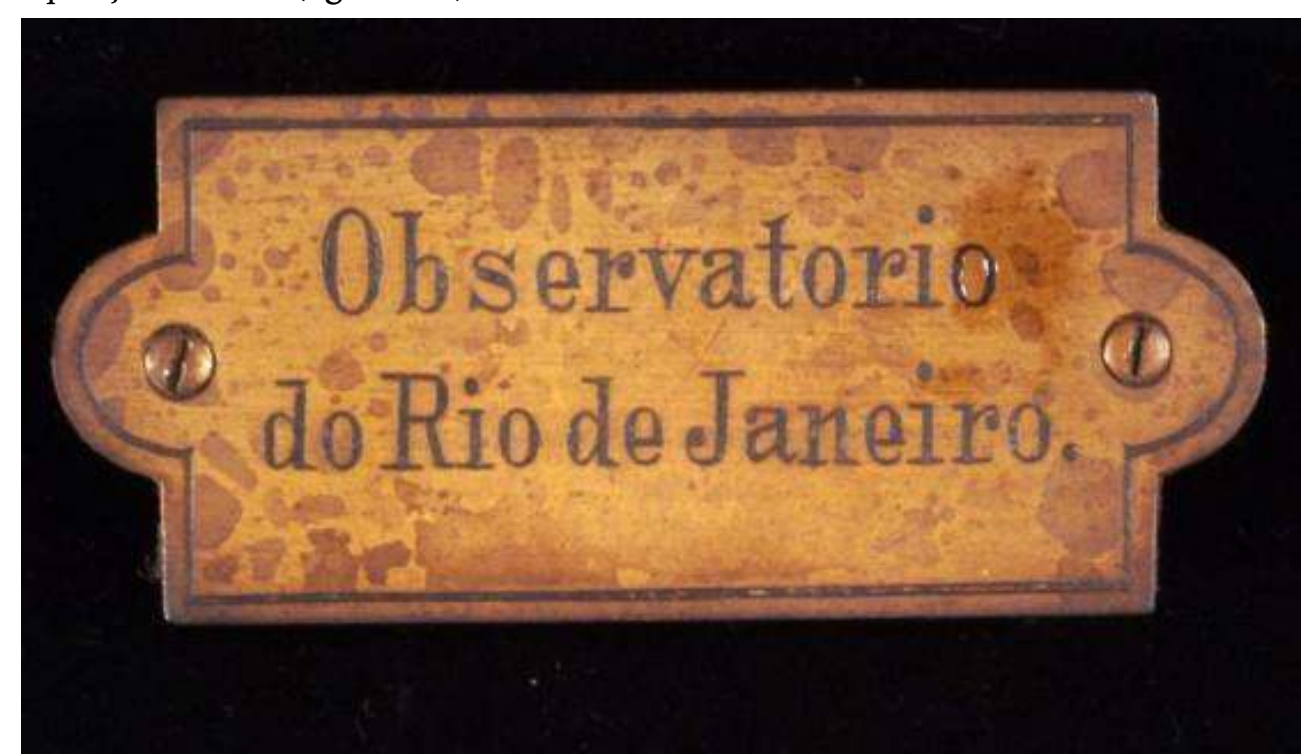

FIg. 5A - PLACAS DO COMPRADOR NO CORPO DA LUNETA 10783 DE BAMBERg, 2012, MAST

FOTOgRAFIA DE RICARDO DIAS 


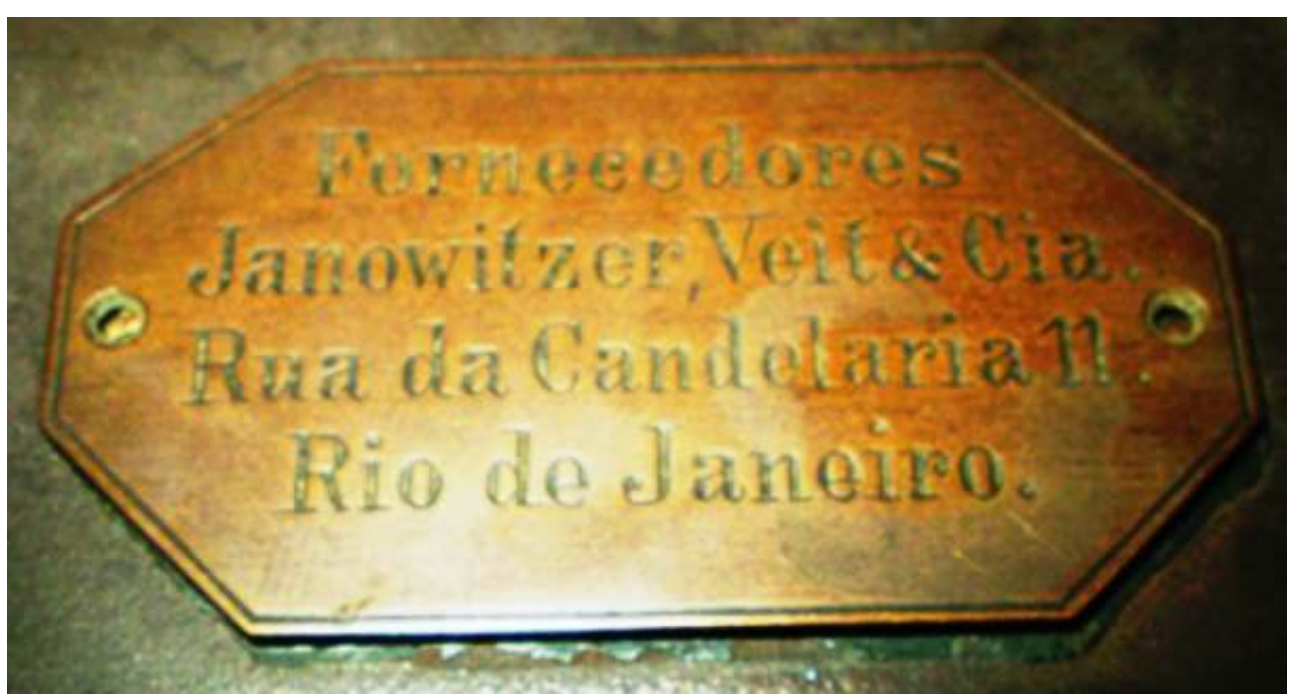

Fig. 5B - PLACA DO FORNECEdOR NO CORPO DA LUNETA 10783 DE BAMBERg, 2012, MAST

FOTOgRAFIA DE RICARDO DIAS

O ON ainda usava a nomenclatura Observatório do Rio de Janeiro, utilizada até 1909, e a famosa empresa JW\&C ainda se chamava JV\&C, de 1886 até 1907. O exame da área escondida sob as placas permitiu a identificação de uma camada pictórica mais antiga na liga de ferro, o verde sob a repintura preta. $O$ exame dos objetos do acervo MAST permitiu inferir que a repintura se dava nas partes da liga de ferro não apenas como renovação do protetivo, mas como renovação da cor segundo o período industrial que se vivia. Outros instrumentos do acervo foram "rejuvenescidos" ou revitalizados, não com a procura de um tom próximo ao original, mas pelo revestimento, que variava do preto ao cinza claro, típico de aparelhos mais recentes do século XX. É importante lembrar que a fase de uso da luneta Bamberg n. 10783 atravessou sete décadas.

37 A inscrição, puncionada pelo fabricante no cubo central da luneta, regista: «CARL BAMBERG FRIEDENAU-BERLIM 10783». Pequenas punções ${ }^{10}$ nas peças, ora pontos com algarismos, ora apenas algarismos, foram observados na desmontagem do instrumento.

o catálogo do fabricante oferece informações sobre os acessórios especiais para determinação de latitude, mas estes acessórios foram incorporados na coleção do Museu e dissociados da luneta. 0 exame em lupa binocular garantiu a confirmação do mesmo tipo de punção Bamberg nas peças dissociadas, onde a variável foi apenas a força do impacto. Em balança analítica de precisão confirmou-se a correspondência exata entre o nível do Talcott e o seu contrapeso.

39 Ao remover o nível do Talcott, naturalmente, o seu contrapeso deveria ser removido. Este facto evidencia que a luneta n.․ 10783 de Bamberg, em algum momento de difícil precisão na sua trajetória, deixou de ser necessária para determinação de latitude. As consultas feitas no Fundo ON no MAST e no Fundo da Hora Legal Brasileira no ON remetem para a segunda década do século XX, quando a luneta zenital de Heyde assumiu esta função. A luneta n. 10783 de Bamberg passou, então, a operar no Serviço Internacional da Hora e nos estudos sobre a irregularidade da rotação da Terra.

Outro exemplo curioso é que a luneta zenital n. 3153 de Gustav Heyde (ON 1920, s/p), fornecida em 1912 ao ON, exibe o tom cinza semelhante ao da luneta acotovelada Askania Ap70 n. 530004 , que começou a ser montada pelo ON em 1953, portanto cerca de 40 anos 
"mais jovem" do que a zenital repintada de modo semelhante. A essas camadas recentes de revestimento também foi então atribuído valor histórico e simbólico.

41 A lente objetiva da luneta não apresenta a inscrição e o número de fábrica. A tampa da objetiva foi adaptada à nova lente, cinco $\mathrm{mm}$ maior, através de três cortes bem distribuídos. Não foi encontrado qualquer documento de baixa, canibalização ${ }^{11}$ para outro instrumento ou transferência de peça para outra instituição. Entretanto, o encarregado das Oficinas, Odílio Ferreira Brandão, anotou a saída da peça no seu caderno de procedimentos e fez três menções a esta canibalização no livro $(1999,36,46,108)$. o resultado desta pesquisa confirma a relevância desta peça de reposição na trajetória de uso do instrumento e apresenta as memórias institucionais que não devem ser apagadas, mesmo que a lente objetiva original seja encontrada em outra instituição. A lente objetiva que passou a integrar o eixo ótico da luneta Bamberg n. 10783 permitiu que esta voltasse a operar, o que é possível verificar pelos diversos relatórios de observação com o instrumento, posteriores à canibalização.

Grande parte das peças da luneta n.. 10783 de Bamberg possui a punção de número 1, à exceção de uma porca n. .6 e outra n. ${ }^{\circ}$, junto a peças provavelmente originais deste lote.

O corpo da luneta Bamberg n.․ 10783 guarda inscrições de algum funcionário, riscadas no verniz da coluna do elevador de inversão do instrumento. $O$ valor simbólico desse dano ao verniz vem sendo estudado. Além dos rabiscos na coluna do elevador, há um pequeno papel atrás da ampola do nível de suspensão em que o número 1,099 está manuscrito. Há algo mais rabiscado, mas alguns atores envolvidos neste empreendimento não julgaram seguro insistir no acesso pelo risco de dano na peça. Alguns pesquisadores vêm testando uma série de hipóteses a respeito dos números documentados no corpo da Bamberg, tanto o detrás da ampola do nível de suspensão como os da coluna do elevador de inversão.

Confrontando os documentos oficiais consultados, as fontes bibliográficas, as entrevistas, os depoimentos e as anotações dos artífices na Oficina de Manutenção dos aparelhos e instrumentos no ON, durante a fase de uso da luneta, e o exame da luneta n.. 10783 de Bamberg como documento da sua própria história, foi possível identificar os seguintes momentos-chave na trajetória do objeto e que constituem a sua cronologia:

1904 - A fábrica Bamberg lança um modelo acotovelado de meridiana na Exposição Universal;

1904 a 1907 - Período em que a luneta n. 10783 de Bamberg deve ter sido adquirida ao fornecedor Janowitzer, Veit \& Cia situado na rua da Candelária, n. ${ }^{\circ}$ 11;

1907 - A luneta estava pronta para ser montada, uma acotovelada com duplo nível e micrómetro elétrico, nas ruínas da Igreja no Morro do Castelo;

1909 (setembro a outubro) - «Para as observações serviu a luneta de passagens fabricada por Bamberg e instalada ao SW do edifício do Observatório. O diâmetro da objetiva do instrumento mede 80mm e sua distância focal $90 \mathrm{~cm}$ (Morize 1987, 169-171);

1910 (fevereiro) - Recomenda-se em relatório técnico: «uma construção pouco dispendiosa, semelhante a existente no Observatório Nacional no pilar oeste do Morro do Castelo para a Bamberg» (ON 1910, 2-3);

1917 - Parafuso do nível da luneta Bamberg partido/luneta Bamberg continua na lista de serviço da oficina/luneta Bamberg sai da lista de pendências da oficina;

1921-1922 - Operação da luneta n.․ 10783 de Bamberg em São Januário na determinação da diferença de longitude «entre o pilar SW do Castelo e o pilar da luneta meridiana do serviço da hora, em S. Januário, utilizados o círculo meridiano portátil 11845 Bamberg e a luneta de passagem 10783 do mesmo fabricante» (Morize 1987, 169-171); 
1963 - Construção do armário embutido no Pavilhão Médio para o material da manutenção de instrumentos (Brandão 1999, 40);

1967 - A luneta Bamberg perde a sua lente objetiva original para um telescópio artesanal construído e levado por um astrónomo militar agregado ao ON;

1970 - A fiação do micrómetro da luneta Bamberg apresentou mau contato;

1974 - Relatório mais recente de observação do céu com a luneta Bamberg deixa nota quanto a uma divergência nos valores de azimute;

1976 (ou um pouco antes) - Quadro de astrónomos reduzido a três em atividade é o motivo apresentado por Oliveiros Tavares para a aposentadoria da luneta Bamberg;

1985/86 - A luneta Bamberg é musealizada e tombada na coleção de instrumentos científicos do MAST e passa a fazer parte do seu acervo;

1993-1994 - Catalogação das partes da luneta Bamberg pelos museólogos do Serviço de Processamento Técnico e Conservação do Acervo do MAST;

2010 - Início das pesquisas sobre a luneta Bamberg para o seu restauro (contexto histórico e funcionamento) e produção de modelo virtual em 3D;

2015 - Modelo virtual encontra-se pronto e o diagnóstico de conservação em fase final.

Como todo o processo de pesquisa e catalogação de objetos de uma coleção museológica, outras informações poderão ser incorporadas no futuro, já que a documentação museológica é dinâmica e continuada.

\section{Considerações finais}

46 As pesquisas desenvolvidas anteriormente demonstraram que o momento de estudo para o restauro de um objeto museológico é um «momento determinante na biografia de qualquer objeto cultural, sendo a ele agregada uma variedade de informações, ampliandose o conhecimento a seu respeito» (Granato e Miranda 2011, 281). Os resultados aqui apresentados reforçam essa afirmação, mostrando o amplo conjunto de informações levantado que apoiou, de forma determinante, as decisões sobre que intervenções seriam válidas para o objeto em estudo.

Neste contexto foi também possível identificar a rede de relações desse objeto com outros objetos da coleção do MAST, enriquecendo as suas biografias e as suas fichas de documentação. A luneta n. 10783 de Bamberg, preservada pelo MAST, na sua longa trajetória operou pelo menos com três círculos meridianos portáteis de Bamberg, com dois cronógrafos, cerca de seis cronómetros, pelo menos com três pendulas, e três lunetas meridianas, uma em cada fase do seu uso (até 1920, até 1961 e até 1974). Foi montada em, pelo menos, três salas, considerando os dois endereços da única instituição em que operou, como instrumento fixo em pilar, entre 1909 e 1974, segundo o mais antigo e o mais recente relatório de observação, encontrados na pesquisa documental.

Ao reconstruir a biografia de um objeto de C\&T devem revelar-se - e revelaram-se processos de institucionalização, relações entre a C\&T e o Estado, coesões e fraturas inter e intrainstitucionais. Toda a poeira levantada nas memórias subterrâneas pela pesquisa sobre essa luneta mostrou que os problemas do passado de uma instituição não são tão distantes nem tão passados. A trajetória de uso da Luneta Bamberg apresenta também alguns vazios. As lacunas de documentação que os geraram devem-se a diversos fatores políticos, económicos, climáticos, académicos - por razões distintas e igualmente relevantes. O número reduzido de trabalhadores no MAST para colocar em dia os 
protocolos museológicos e arquivísticos não é uma novidade para o mundo dos museus e interfere de forma determinante para os contextos de uso dos objetos das coleções.

A canibalização da lente objetiva da luneta n.. 10783 de Bamberg não será apagada da história do ON porque as peças de reposição que a luneta trouxe da sua trajetória de uso são consideradas documentos relevantes.

50 A estrutura cronológica desta pesquisa prestou-se à análise de comportamentos e situações interrelacionadas no $\mathrm{ON}$ - a única instituição que utilizou a luneta meridiana acotovelada n.. 10783 de Bamberg -, apoiando a determinação da carga simbólica dos danos materiais identificados na luneta, pois ocorreram no âmbito das relações sociais em que este objecto operou, enriquecendo os aspetos a serem apresentados na sua museografia.

\section{BIBLIOGRAFIA}

"Dossiê temático" [sobre o Centenário da reforma Pereira Passos]. 2003. Revista Rio de Janeiro 10 (maio-agosto): 77-109. http://www.forumrio.uerj.br/documentos/revista_10/10-Wagner.pdf Alberti, Samuel. 2005. “Objects and the Museum.” Revista Isis 96 (4): 559-571. Armando, P. C. 1959. “Uma Mulher lê a Hora Exata nas Estrelas.” A Cigarra Magazine 12-13. Bamberg, Paul. 1904. "Bamberg." In Elementary and Advanced Education: German Educational Exhibition, World's Fair St. Louis, 7-11. Berlin: W. Buxenstein.

Barroso Jr., Jair. 2011. Palestra proferida no Pavilhão da Luneta Meridiana Askania, no Museu de Astronomia e Ciências Afins (MAST), Rio de Janeiro. Filmagem: Eugênio Reis, (48 min, 26 s). Rio de Janeiro: MAST, 13 de setembro de 2011. DVD. Palestra aberta concedida às Coordenações de Educação em Ciências, História da Ciência e Museologia do Museu de Astronomia e Ciências Afins (MAST).

Barroso Jr., Jair. 1961. Instalação, Retificação e Determinação das Constantes da Luneta Meridiana Askania Ap. 70, n.․530004, do Observatório Nacional. Rio de Janeiro: SEDEGRA Sociedade Editora e Gráfica.

Barroso Jr., Jair. 2013. Entrevista conduzida pela conservadora Márcia Pinheiro Ferreira no mês de janeiro no Museu de Astronomia e Ciências Afins (MAST), Rio de Janeiro. Material não publicado.

Brandão, Odílio Ferreira. 1999. Os Meus 40 Anos de Observatório Nacional. Rio de Janeiro: MAST (Museu de Astronomia e Ciências Afins).

Brasil. 1908. Relatório do Ministério das Indústrias, Viação e Obras Públicas em 1908, referente ao ano findo 1907. http://brazil.crl.edu/bsd/bsd/u1988/000490.html

Fotografias de Augusto Malta. [2016]. Acervo Augusto Malta. Rio de Janeiro: Arquivo Geral da Cidade do Rio de Janeiro. http://portalaugustomalta.rio.rj.gov.br/acervo-obra/observatorioastronomico-morro-do-castelo (consultado em dezembro 23, 2016). 
Fotografias de Augusto Malta. [2016]. Acervo Pedro Correa do Lago. http://

brasilianafotografica.bn.br/brasiliana/handle/bras/2733 (consultado em abril 26, 2016).

Granato, Marcus, e Cláudia Penha dos Santos. 2010. "O Museu de Astronomia e Ciências Afins e suas Coleções." In Coleções Científicas Luso-Brasileiras: Patrimônio a ser Descoberto, org. por Marcus Granato e Marta Lourenço, 47-68. Rio de Janeiro: MAST.

Granato, Marcus, e Françoise Le Guet Tully. 2009. "Les Principes de la Restauration d'Instruments Scientifiques: Le Cas du Cercle Méridien Gautier de l'Observatoire de Rio de Janeiro." In Situ: Revue des Patrimoines 10. http://insitu.revues.org/3865

Granato, Marcus, e Luiz Roberto Martins de Miranda. 2011. “A Restauração na Trajetória de um Teodolito do Acervo do MAST.” Anais do Museu Paulista: História e Cultura Material 19 (1): 279-312.

International Comet Quarterly. [2016]. Glossary of (comet and) astronomical terms. Harvard: UH/ Department of Earth and Planetary Sciences. www.icq.eps.harvard.edu/ICQGlossary.html (consultado em outubro 12, 2016).

Kopytoff, Igor. 1986. “The Cultural Biography of Things: Commoditization as Process.” In The Social Life of Things: Commodities in Cultural Perspetive, ed. Arjun Appadurai, 64-93. Cambridge: Cambridge University Press.

Morize, Henrique. 1987. Observatório Astronômico: Um Século de História (1827-1927). Coleção Documentos de História da Ciência, 1. Rio de Janeiro: MAST e Salamandra.

Mourão, Ronaldo Rogério de Freitas. 1995. Dicionário Enciclopédico de Astronomia e Astronáutica. 2. ed. Rio de Janeiro: Lexikon.

ON. 1904. Ofício n.. 73 de 10 de junho de 1904, do diretor do ON solicita ao diretor da Estrada de Ferro Central do Brasil. ON (Observatório Nacional).

ON. 1910. Relatório de Visita Técnica 1 de fevereiro de 1910 ao ON, sobre as instalações do Observatório da Marinha na Ilha do Rijo. ON (Observatório Nacional).

ON. 1913 Ofício n.ำ 200 de 3 de abril de 1913, referente à encomenda dos pavilhões meridianos de Zeiss à JW\&C. ON (Observatório Nacional).

ON. 1914a. Ofício n.ำ 140 de 4 de abril de 1914, referente às ferragens de Zeiss que já haviam chegado. ON (Observatório Nacional).

ON. 1914b. Ofício n.o 260 de 13 de junho de 1914, referente à falta de proteção para as ferragens de Zeiss até a montagem dos pavilhões meridianos. ON (Observatório Nacional).

ON. 1914c. Ofício n.ำ 504 de 11 de novembro de 1914, referente ao reinício da construção dos pavilhões meridianos. ON (Observatório Nacional).

ON. 1914d. Ofício n.ำ57 de 5 de dezembro de 1914, referente à indeterminação de prazo para vinda dos montadores da Zeiss. ON (Observatório Nacional).

ON. 1915a. Ofício n.․592 de 11 de outubro de 1915, referente ao mesmo assunto. ON (Observatório Nacional).

ON. 1915b. Ofício n. 595 de 15 de outubro de 1915, referente à ferrugem nas peças metálicas de Zeiss expostas às intempéries. ON (Observatório Nacional).

ON. 1916a. Ofício n.ำ 37 de 19 de janeiro de 1916, referente às goteiras nos novos pavilhões em São Januário. ON (Observatório Nacional).

ON. 1916b. Ofício n.. 743 de 14 de novembro de 1916, referente à humidade e à infestação de cupins no madeiramento dos pequenos pavilhões meridianos. ON (Observatório Nacional). 
ON. 1917. Anuário do Observatório 1917. ON (Observatório Nacional).

ON. 1920. Inventário de Bens Imóveis, 1920. ON (Observatório Nacional).

ON. 1954. Ofício de 10 de março de 1954, referente às pesquisas do ON de interesse do Comité Spécial de l'Ánnée Geophysique Internationalle, anexo ao Ofício n. ${ }^{\circ} 175$ do ON ao CNPq, 19 de agosto de 1954. ON (Observatório Nacional).

ON. 1974. Boletim de Observação Meridiana (setembro 25, 1974), Arthur Almeida, luneta Bamberg. ON (Observatório Nacional).

Soares, Bruno Brulon. 2017. "Paisagens Culturais e os Patrimônios Vividos: Vislumbrando a Descolonização, para uma Musealização Consciente." Revista Museologia e Patrimônio 10 (1): 65-86.

Tavares, Oliveiros Cardoso, e Odílio Ferreira Brandão. 1993. Entrevista conduzida pela jornalista Jusselma Duarte e pela museóloga Cláudia Penha dos Santos a 7 de abril de 1993, no Museu de Astronomia e Ciências Afins (MAST), Rio de Janeiro. Filmagem de Durval Costa, reformatação de VHS para DVD, $44 \min 39$ s. 1 DVD.

Wolfschmidt, Gudrun. 2012. "Telescopes Made in Berlin: From Carl Bamberg to Askania.” In From Earth-Bound to Satellite: Telescopes, Skills and Networks, ed. Alison D. Morrison-Low, et. al, 177-195. Leiden: Brill.

\section{NOTAS}

1. Esta proposta foi crescendo em estudos antropológicos na década de 1990, a partir de Kopytoff (1986). Alberti (2005) comentou o impacto, já em 1989, desta proposta nas reflexões de Susan Pearce e de Charles Saumarez Smith.

2. Processo n. ${ }^{\circ}$ 1009-T79/IPHAN, Livro Histórico, volume 1, folhas 94-97, inscrição 509, de 14-08-1986 (Granato e Santos 2010, 50).

3. International Comet Quarterly Glossary. Harvard: UH/Department of Earth and Planetary Sciences. www.icq.eps.harvard.edu/ICQGlossary.html (consultado em outubro 12, 2016).

4. Abertura descrita pelo assistente-chefe Domingos Fernandes da Costa no trecho do relatório de determinação de latitude do Morro do Castelo em 1909, transcrito por Morize $(1987,171)$.

5. Para mais informações sobre a história do Observatório ver Granato e Tully (2009).

6. Para saber mais sobre o tema, ver: "Dossiê temático" [sobre o Centenário da reforma Pereira Passos] (2003).

7. Em ótica, colimação é o processo que permite tornar paralelos os raios luminosos de um feixe. [...] (Mourão 1995, 180).

8. Aos 23 min e $25 \mathrm{~s}$ do documento audiovisual total da entrevista.

9. A coleção de anuários do Observatório, onde estão publicados os boletins da Hora e da Meteorologia, está disponível para consulta na biblioteca do ON.

10. Punções e matrizes são utensílios que, ao sofrer impacto contra um material, produzem uma concavidade cujo perfil pode ser identificado pelo tato ou pelo contraste entre luz e sombra. No estudo de objetos de C\&T históricos, é possível encontrar marcas resultantes da ação de punções com o nome do fabricante e com o número de série do exemplar fabricado e com signos indicativos de correspondência no encaixe de peças. 
Todas estas inscrições são gravadas nas peças metálicas. Estas punções são, geralmente, confecionadas em liga metálica mais dura do que o material a ser gravado.

11. Termo utilizado para as situações em que peças e partes de instrumentos científicos são retiradas para substituir outras de um outro instrumento que se danificaram e permitir que esse similar funcione. Assim, um instrumento é destacado para ser "canibalizado" e permitir que outro(s) funcione(m).

\section{RESUMOS}

Este artigo apresenta resultados relacionados com a pesquisa sobre uma luneta meridiana acotovelada, com o número 10783, fabricada por Bamberg, e pertencente à coleção do Museu de Astronomia e Ciências Afins (MAST), no Rio de Janeiro (Brasil). O estudo desenvolveu-se no âmbito do programa de conservação do sítio de observação do céu, preservado pelo MAST, pertencente originalmente ao Observatório Nacional (ON). A partir da necessidade de intervenção curativa na luneta n. 10783 (considerada urgente pelo seu mau estado de conservação), foram pesquisadas fontes primárias e secundárias que permitissem a construção da trajetória do uso do objecto (1907-2016) e, assim, auxiliar nas decisões para o seu restauro. A metodologia utilizada baseou-se nos saberes teóricos transversais à conservação e à biografia cultural das coisas, destacando-se alguns relatórios e depoimentos de antigos funcionários do ON; na consulta a fontes primárias e na análise do próprio objeto. Além disso, foram identificadas e analisadas fontes secundárias em bibliotecas e bancos digitais de publicações académicas sobre aspetos relacionados com este instrumento astronómico. A partir dos dados recolhidos, foi possível verificar que o instrumento esteve em operação cerca de 70 anos, identificando-se vários factos relacionados com a sua trajetória. A partir de 1985, a luneta Bamberg foi tombada na coleção de instrumentos científicos do MAST e passou a fazer parte do seu acervo, sendo sempre mantida no pavilhão astronómico, local original da sua utilização.

This article presents results related to the research on an elbow transit telescope, number 10783, manufactured by Bamberg, and belonging to the MAST (Museum of Astronomy and Related Sciences) collections. The study was developed within the framework of the conservation program of the sky observation site, safeguarded by MAST, in Rio de Janeiro (Brazil), and originally belonging to the Observatório Nacional - ON. From the need for curative intervention in this object (considered urgent due to its poor conservation status), primary and secondary sources were investigated that could allow the construction of the trajectory of its use (1907-2016) and, thus, assist in the decisions for its conservation. The methodology used was based on the theoretical knowledge transversal to the conservation and the cultural biography of things, highlighted by some reports and statements of former employees of the ON who worked with the instrument; research on primary sources; and the analysis of the object itself. In addition, secondary sources were identified and analysed in libraries and digital databases of academic publications on aspects related to the instrument. From the data collected, it was possible to verify that the instrument was in operation for about 70 years, with the identification of several facts related to its trajectory of original use. Since 1985, the Bamberg telescope has been included in the collection of scientific instruments of MAST and has become part of its collection and has always been kept in the astronomical pavilion, the original place of its use. 


\section{ÍNDICE}

Palavras-chave: Museu de Astronomia e Ciências Afins (Brasil), luneta Bamberg, biografia de objecto, coleção científica, história da ciência

Keywords: Museum of Astronomy and Related Sciences (Brazil), object biography, Bamberg elbow transit telescope, history of science, scientific collection

\section{AUTORES}

\section{MÁRCIA PINHEIRO FERREIRA}

Mestre em Preservação de Acervos de Ciência e Tecnologia pelo Museu de Astronomia e Ciências Afins (MAST), Brasil. Conservadora de bens móveis da Fundação Casa de Rui Barbosa, Rio de Janeiro. Tem desenvolvido pesquisa na área da conservação de colecções e preservação de bens móveis no Museu Casa de Rui Barbosa.

Fundação Casa de Rui Barbosa, Museu Casa de Rui Barbosa, Rua São Clemente, 134, CEP.:

22.260-000, Rio de Janeiro, Brasil, marcia@rb.gov.br

\section{MARCUS GRANATO}

Doutor em Engenharia Metalúrgica pela Universidade Federal do Rio de Janeiro (Brasil).

Coordenador da área de Museologia no Museu de Astronomia e Ciências Afins (MAST) desde 2004, docente e vice-coordenador do programa de pós-graduação em Museologia e Património da Universidade Federal do Estado do Rio de Janeiro (UNIRIO)/MAST. Desenvolve pesquisa na área do património científico e da conservação.

Museu de Astronomia e Ciências Afins, Rua General Bruce, 586, CEP.: 20921-030, Rio de Janeiro, Brasil, marcus@mast.br 